\title{
Transient thermal process induced by swift heavy ions: Defect annealing and defect creation in $\mathrm{Fe}$ and $\mathrm{Ni}$
}

\author{
Ch. DUFOUR, Z G WANG ${ }^{\dagger}$, E PAUMIER ${ }^{\dagger \ddagger}$ and M TOULEMONDE* ${ }^{*^{\dagger}}$ \\ LERMAT, ESA 6004, ISMRa, Campus II, Bd Mal Juin, 14050 Caen Cedex, France \\ ${ }^{\dagger}$ CIRIL, UMR 6637, CEA-CNRS, Rue Claude Bloch, BP5133, 14070 Caen Cédex 5, France \\ ${ }^{\ddagger}$ Also at LERMAT, ESA 6004, ISMRa, Campus II, Bd Mal Juin, 14050 Caen Cedex, France \\ *Present Address: Institute of Modern Physics, Academia Sinica, 253 Nanchang Road, 730000 Lanzhou, People's \\ Republic of China
}

\begin{abstract}
In the present paper, a method is proposed to quantitatively estimate the nuclear defect annealing by the electronic stopping power $S_{e}$. The spatial distribution of defects created in metals by nuclear collisions is known from numerical calculation based on the binary collisions with screened Coulomb potential. In the framework of the thermal spike model, $S_{\mathrm{e}}$ induced annealing of nuclear defects is simulated without considering athermal recombination. These calculations are applied to iron and nickel. The agreement between experiment and simulation in iron allows to determine the electron-phonon coupling value for iron. The defect creation by $S_{\mathrm{e}}$ arises when the energy deposited on the atoms overcomes the energy necessary to melt the material.
\end{abstract}

Keywords. Transient thermal process; heavy ions; defect annealing; defect creation.

\section{Introduction}

Recent progress in understanding the metals sensitivity (Iwase et al 1985, 1986, 1987, 1988, 1990, 1992a, b; Dunlop and Lesueur 1989, 1992, 1993; Dunlop et al 1987, 1988, 1989a, b, 1990, 1991, 1994; Paumier et al 1989a, b, 1992, 1993; Barbu et al 1992; Henry et al 1992; Dammak et al 1993a, 1995; Dufour 1993; Dufour et al 1993, 1996; Dammak 1994; Iwase and Iwata 1994; Wang et al 1996a) under swift heavy ion irradiations in the electronic stopping power $\left(S_{\mathrm{e}}\right)$ regime are the following: (i) the damage efficiencies in $\mathrm{Cu}, \mathrm{W}$ and $\mathrm{Ag}$ obtained from low temperature irradiation experiments are nearly independent on the electronic stopping power (Iwase et al 1987; Dunlop and Lesueur 1993; Dufour et al 1996), (ii) at low values of $S_{\mathrm{e}}$ the damage efficiencies in iron and nickel irradiated at low temperature decrease with increasing $S_{e}$ (Iwase et al 1987, 1988, 1990, 1992a; Dunlop et al 1989a, 1994; Dunlop and Lesueur 1992, 1993; Dammak 1994; Iwase and Iwata 1994). Furthermore, above a $S_{\mathrm{e}}$ critical value, the damage efficiency in iron increases with $S_{\mathrm{e}}$ (Dunlop et al 1989a, 1990 , 1994; Dunlop and Lesueur 1992, 1993; Dammak 1994) and (iii) a strong damage creation induced by $S_{\mathrm{e}}$ is observed in $\mathrm{Ti}, \mathrm{Co}, \mathrm{Zr}$ and $\mathrm{Bi}$ under swift heavy ion irradiations (Dunlop et al 1989a, 1991; Dunlop and Lesueur 1992, 1993; Dufour 1993; Dufour et al 1993;

\footnotetext{
*Author for correspondence
}

Paumier et al 1993; Dammak 1994; Wang et al 1996a). When irradiated by swift heavy ions (Dufour 1993; Dufour et al 1993; Paumier et al 1993), bismuth becomes highly resistive as already observed from recrystallization of amorphous film (Hamada et al 1981). $S_{c}$ induced phase change in titanium is observed (Dammak et al 1993a; Dammak 1994). Tracks in titanium and zirconium are observed by high resolution electron microscopy (Henry et al 1992; Dammak et al 1995).

Two models describing the energy transfer process between the incident ion and the target, Coulomb explosion and thermal spike, have been proposed to explain the experimental phenomena induced by $S_{c}$ (Dunlop et al 1991, 1994; Toulemonde et al 1992, 1993, 1996; Dammak 1993a, b; Dufour 1993; Dufour et al 1993; Dunlop and Lesueur 1993; Lesueur and Dunlop 1993; Wang et al 1995, 1996a). The Coulomb explosion model (Fleischer et al 1975) was qualitatively used in insulators and organic materials (Bitensky and Parilis 1987) and was recently extended to metallic systems (Dunlop et al 1991, 1994; Dammak et al 1993a,b; Dunlop and Lesueur 1993; Lesueur and Dunlop 1993; Dammak 1994) especially the ones exhibiting soft phonon modes (Dunlop et al 1991; Lesueur and Dunlop 1993). The thermal spike model was also developed in metals (Seitz and Koehler 1956; Toulemonde et al 1992, 1993; Dufour et al 1993, 1996; Wang et al 1994, 1995) as well as in insulators (Chadderton and Montagu-Pollock 1969; Meftah et al 1994). 
The aim of the present paper is to quantitatively simulate $S_{\mathrm{c}}$ induced defect annealing and defect creation threshold by the use of the thermal spike model and then to explain the different points quoted above. Nuclear defect production rates induced by irradiations have been studied for many metals (Corbert et al 1959; Coltman et al 1967; Delaplace et al 1968; Bauer et al 1969; Simpson and Chaplin 1969; Dibbert et al 1972; Lampert and Schaefer 1972; Maury et al 1973, 1976; Birtcher et al 1974; Forsch et al 1974; Knöll et al 1974; Dausinger and Schultz 1975; McIlwain et al 1975; Myhra and Gardiner 1975; Wells and Russell 1976; Averback and Merkle 1977; Dural et al 1977; Nakagawa et al 1977; Vajde 1977; Young 1978; Dunlop et al 1982, 1987, 1988, 1989b; Iwase et al 1985, 1986, 1987, 1988, 1990, 1992a, b; Bois and Beuneu 1989; Dunlop and Lesueur 1989; Henry et al 1992; Dammak et al 1993a; Dammak 1994; Iwase and Iwata 1994). In these materials, the thermal stability of defects created by nuclear collisions has been studied by thermal annealing after irradiations. Using the analysis proposed by Vineyard (1976) and knowing the temperature along the ion path (Toulemonde et al 1992, 1993; Dufour et al 1993; Wang et al 1994, 1995 ), the number of nuclear defects annealed by $S_{\mathrm{e}}$ can be numerically simulated. For this purpose it is necessary to know the activation energies for stage $I$ annealing in metals (Knöll et al 1974; Wells and Russell 1976) and the spatial distribution of nuclear defects (Wang et al 1996b). Then the ratio of the number of nuclear defects after $S_{\mathrm{e}}$ annealing to its initial value can be calculated and compared with the experimental damage efficiency. The calculation will be applied to experimental results in iron (Dunlop et al 1994) and nickel (Iwase et al 1988).

\section{Nuclear defect annealing}

The basic idea of the model is based on a two-step process: First the nuclear collisions lead to atomic displacements (Biersack and Haggmark 1980) in a time of $\sim 10^{-13}$ to $10^{-12} \mathrm{~s}$ (Diaz de la Rubia and Guina 1991).
Then the defect annealing is induced by the electron energy relaxation on the lattice in a time of $10^{-12}$ to $10^{-11} \mathrm{~s}$. During the first step, a primary recoil atom initiates a collision cascade leading to a spatial distribution of self-interstitial atoms (SIA) (Wang et al 1996b). During the second step, the energy deposited on the electrons is transferred to the lattice causing a local heating. Calculating the spatial lattice temperature distribution and using the Vineyard model (Vineyard 1976), one can calculate the resulting nuclear defect distribution.

As the present paper is an extension of a previous one (Wang et al 1996b), we shall concentrate only on two new developments: (i) the different activation energies of the substage of the stage $I$ in iron have been taken into account (table 1) and (ii) this calculation is applied to the nickel.

\subsection{Defect annealing by $S_{e}$ induced thermal spike}

An annealing of the substage s of stage $I$ is characterized by its activation energy $E_{\mathrm{a}}$. A defect created at a distance $r$ from the ion path may be annealed at a time $t$ with a jump frequency $\nu_{\mathrm{s}}(r, t)$

$$
\nu_{\mathrm{s}}(r, t)=\nu_{0} \exp \left[-E_{\mathrm{a}} / T_{1}(r, t) / k_{\mathrm{B}}\right]
$$

where $T_{1}(r, t)$ is the lattice temperature at radius $r$ and time $t, v_{0}=T_{\mathrm{D}} k_{\mathrm{B}} / h$ the Debye phonon frequency, $T_{\mathrm{D}}$ the Debye temperature. $k_{\mathrm{B}}$ and $h$ are the Boltzmann's and Plank's constants. The annealing probability during time interval $\Delta t$ is $\nu_{\mathrm{s}}(r, t) \Delta t$. The residual SIA remain at radius $r$ with the probability

$$
P_{\mathrm{s}}(r)=\Pi\left[1-\nu_{\mathrm{s}}(r, t) \Delta t\right]
$$

where $\Pi$ is the product of all the probabilities on the time. Considering that there are several substages, the total probability of remaining SIA at radius $r, P_{\mathrm{T}}(r)$, is obtained by summing the probabilities corresponding to each substage:

Table 1. Parameters of iron and nickel used in the calculations.

\begin{tabular}{lcccr}
\hline Metal & Substage & $\begin{array}{c}\text { Temperature } \\
\text { range } T(\mathrm{~K})\end{array}$ & $\begin{array}{c}\text { Activation energy } \\
E_{\mathrm{a}}(\mathrm{eV})\end{array}$ & $\eta_{\mathrm{s}}(\%)$ \\
\hline & $\mathrm{I}_{\mathrm{A}}$ & $40 \sim 55$ & $\sim 0.05$ & 6 \\
& $\mathrm{I}_{\mathrm{B}}$ & $55 \sim 75$ & $0.10 \pm 0.02$ & 17 \\
Iron (Wells and & $\mathrm{I}_{\mathrm{C}}$ & $75 \sim 93$ & $0.19 \pm 0.02$ & 16 \\
Russel 1976) & $\mathrm{I}_{\mathrm{D}}$ & $93 \sim 110$ & $0.23 \pm 0.02$ & 40 \\
& $\mathrm{I}_{\mathrm{E}}$ & $110 \sim 135$ & $0.25 \pm 0.03$ & 21 \\
Nickel (Knöll & & & & 100 \\
et al 1974) & $\mathrm{I}_{\mathrm{D}+\mathrm{E}}$ & $50 \sim 67$ & $0.140 \pm 0.015$ & \\
\hline
\end{tabular}




$$
P_{\mathrm{T}}(r)=\Sigma \eta_{\mathrm{s}} P_{\mathrm{s}}(r)
$$

where $s(=1,2, \ldots, n)$ the substage and $\eta_{\mathrm{s}}$ is the percentage of defects created in sth substage to the total number of defects in stage 1 (table 1).

Numerous experiments of defect annealing have been performed on metals after $\mathrm{MeV}$ electron irradiations (McIlwain et al 1975; Myhra and Gardiner 1975; Vajda 1977; Young 1978; Bois and Beuneu 1989). Only the stage $I$ and its substages will be considered in the following. In table 1 the useful parameters of iron and nickel (Wells and Russel 1976; Vajda 1977; Young 1978) are reported with the $\eta_{\mathrm{s}}$ ratios. The $\nu_{0}$ value of iron and nickel is given in table 2 .

\section{$2.2 S_{e}$ induced thermal spike: lattice temperature distribution}

According to the previous descriptions (Toulemonde et al 1992, 1993; Dufour 1993; Dufour et al 1993; Wang et al 1995, 1996a), the energy relaxation during the process induced by electronic energy loss is due to the electron-electron and electron-atom interactions. It could be described mathematically by two coupled differential equations governing the energy diffusion in the two subsystems (electrons and lattice) and their coupling:

$$
\begin{aligned}
& C_{\mathrm{e}}\left(T_{\mathrm{e}}\right) \frac{\partial T_{\mathrm{e}}}{\partial t}=\nabla\left(K_{\mathrm{e}}\left(T_{\mathrm{e}}\right) \nabla T_{\mathrm{e}}\right)-g\left(T_{\mathrm{e}}-T_{\mathrm{l}}\right)+A(r, t), \\
& C_{\mathrm{l}}\left(T_{1}\right) \frac{\partial T_{1}}{\partial t}=\nabla\left(K_{\mathrm{l}}\left(T_{1}\right) \nabla T_{1}\right)+g\left(T_{\mathrm{e}}-T_{\mathrm{l}}\right),
\end{aligned}
$$

where $T_{e}, T_{1}, \mathrm{C}_{\mathrm{e}}, \mathrm{C}_{1}$ and $\mathrm{K}_{\mathrm{e}}, \mathrm{K}_{1}$ are the temperature, the specific heat and the thermal conductivity of the electronic and atomic systems respectively, $A(r, t)$ is the energy density supplied by the incident ions to the electronic system at radius $r$ and time $t$ such that

$$
2 \pi r A(r, t) \mathrm{d} r d t=S_{\mathrm{e}}
$$

$g$ is the electron-phonon coupling factor (Kaganov et al 1957; Kittel 1983; Allen 1987; Dufour 1993; Wang et al 1995; Dufour et al 1996). The temperatures of the electronic and atomic systems, $T_{\mathrm{e}}(r, t)$ and $T_{1}(r, t)$ are numerically calculated at each time $t$ and radius $r$.

Table 2. Atomic density $n_{\mathrm{a}}$, Debye temperature $T_{\mathrm{D}}$ and Debye frequency $v_{0}$ of phonon jump of iron and nickel.

\begin{tabular}{lccc}
\hline Metal & $n_{\mathrm{a}}\left(10^{22} \mathrm{~cm}^{-3}\right)$ & $T_{\mathrm{D}}(\mathrm{K})$ & $v_{0}\left(10^{12} \mathrm{~Hz}\right)$ \\
\hline Iron & 8.48 & 470 & 9.79 \\
Nickel & 9.14 & 450 & 9.37 \\
\hline
\end{tabular}

For iron irradiated at $20 \mathrm{~K}$ with $1.32 \mathrm{GeV} \mathrm{Kr}$ ions and using a $g$ value equal to $1.44 \times 10^{12} \mathrm{~W} \mathrm{~cm}^{-3} \mathrm{~K}^{-1}$ (Wang et al 1994, 1995), figure 1 shows the calculated probabilities of remaining defects $P(r)$ in the different substages $s$ of stage I characterized by their activation energies. The final SIA density $N_{\mathrm{f}}(r)$ after $S_{\mathrm{c}}$ annealing is given as

$$
N_{\mathrm{f}}(r)=P_{\mathrm{T}}(r) N_{\mathrm{i}}(r)
$$

where $N_{\mathrm{i}}(r)$ is the initial density of defects of stage I at radius $r$ before $S_{\mathrm{e}}$ annealing (figure 2). Then the total number of residual defects, $N_{\text {df }}$, is calculated by an integration over $r$. From figures 1 and 2, we can see that the defect annealing mainly occurs close to the ion path.

\section{Damage efficiency and comparison with experiments}

\subsection{Application to iron}

We define the theoretical damage efficiency $\xi_{\text {cal }}$ as the ratio:

$$
\xi_{\text {cal }}=N_{\mathrm{dr}} / N_{\mathrm{di}},
$$

where $N_{\mathrm{di}}$ is the initial number of nuclear defects created before any annealing (Wang et al 1996b) and correspond

$$
1.32 \mathrm{GeV} \mathrm{Kr} \text { ion in iron with } S \doteq 16 \mathrm{kev} \mathrm{nm}^{-1}
$$

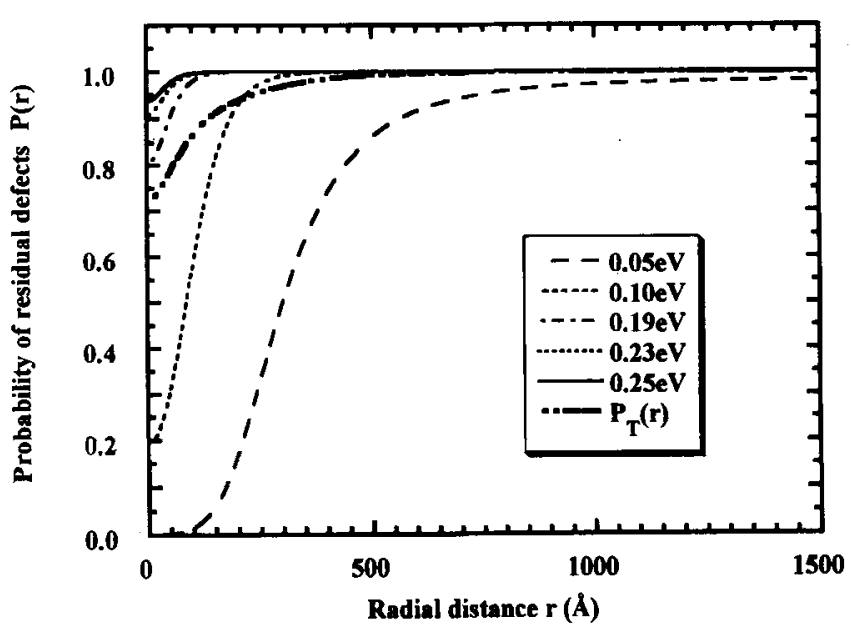

Figure 1. Calculated probability of residual defects by $S_{c}$ in iron versus radial distance for the different substages of the stage I characterized by their activation energy. Initial conditions of the calculations: Iron target is irradiated with $1.32 \mathrm{GeV} \mathrm{Kr}$ ions at $20 \mathrm{~K}, S_{\mathrm{e}}=16.0 \mathrm{keV} / \mathrm{nm}$ and the electron-phonon coupling at $300 \mathrm{~K}$ is $g=1.44 \times 10^{12} \mathrm{~W} \mathrm{~cm}^{-3} \mathrm{~K}^{-1}$ (Wang et al 1994, 1995). The quoted activation energies are from table 1 . 


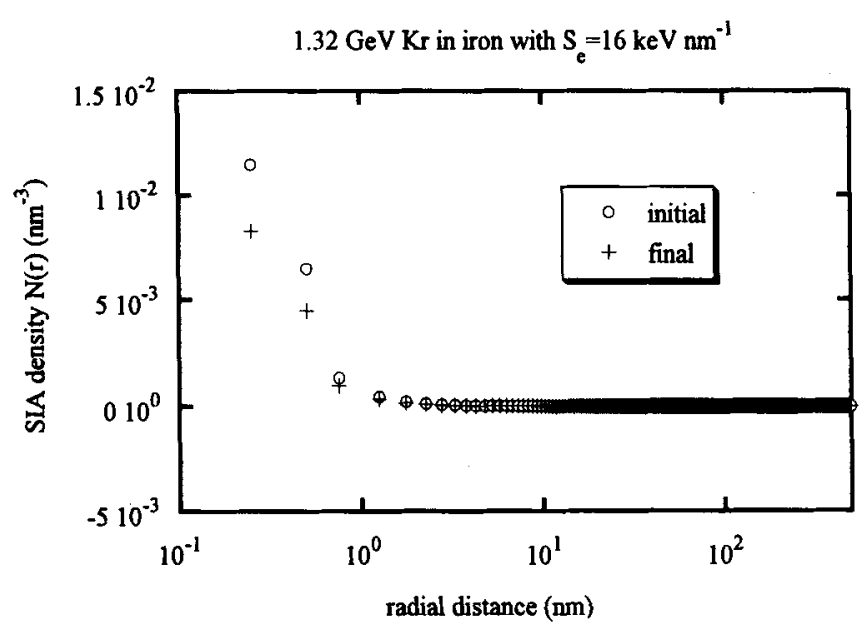

Figure 2. Calculated SIA distributions before $\left(N_{i}(r)\right)$ and after $\left(N_{f}(r)\right) S_{e}$; induced thermal annealing. The initial conditions of calculation are the same as in figure 2 and $N_{\mathrm{f}}(r)=P_{\mathrm{T}}(r) N_{\mathrm{i}}(r)$. Defect annealing by $S_{\mathrm{e}}$ mainly occurs within $1 \mathrm{~nm}$ around the ion path.

to the integration over $r$ of $N_{\mathrm{i}}(r)$ (figure 2). In the regime of $S_{\mathrm{e}}$ induced defect annealing, $\xi_{\text {cal }}$ should correspond to the experimental damage efficiency $\xi_{\text {exp }}$ (Dunlop et al 1994).

In figure 3 , the comparison between $\xi_{\text {cal }}$ and $\xi_{\text {exp }}$ is given for iron with $g=1.44 \times 10^{12} \mathrm{~W} \mathrm{~cm}^{-3} \mathrm{~K}^{-1}$. It shows that $\xi_{\text {cal }}$ (curve A) and $\xi_{\text {exp }}$ seem to be linked by $\xi_{\text {exp }} / \xi_{\text {cal }}=F$, where $F$ is a constant. For iron, $\xi_{\text {cal }}^{\prime}=F \xi_{\text {cal }}$ (curve $\mathrm{A}^{\prime}$ ) with $F=0.45$. This factor between the experimental damage efficiency and the theoretical ones might come from the fact that we have not taken into account the athermal defect recombination in the cascades. The curves (figure 3 ) show that by using a complete set of input data (table 1) for the different substages of stage I, the calculation can describe the slight decrease of the damage efficiency between 2 and $15 \mathrm{keV} \mathrm{nm}^{-1}$, contrary to the simple calculation (Wang et al 1996b). Moreover, the damage efficiency evolution at higher value of $S_{\mathrm{e}}$ is very closely followed as well as the kick around $25 \mathrm{keV} \mathrm{nm}^{-1}$. In the thermal spike model, for the same $S_{\mathrm{e}}$, lower the beam energy, higher the temperature along the ion path, leading to stronger annealing. This can explain that at $2.6 \mathrm{MeV} \mathrm{amu}{ }^{-1} \mathrm{Kr}$ beam the damage efficiency is lower than with $21.8 \mathrm{MeV} \mathrm{amu}{ }^{-1} \mathrm{Xe}$ beam. Such a velocity effect was previously observed for damage creation (Wang et al 1996a, b).

Extrapolating the calculation to even higher value of $S_{\mathrm{e}}$ (figure 4), the energy necessary to melt is reached at $49 \mathrm{keV} \mathrm{nm}^{-1}$ with a beam energy of $12 \mathrm{MeV} \mathrm{amu}^{-1}$, intermediate energy between the values quoted in figure 4. Such a $S_{e}$ value corresponds to the appearance of defect creation (Dunlop et al 1994) in the electronic stopping power regime. Such a correlation supports the use of the appearance of a melt phase as a criterion for defect creation in metals.

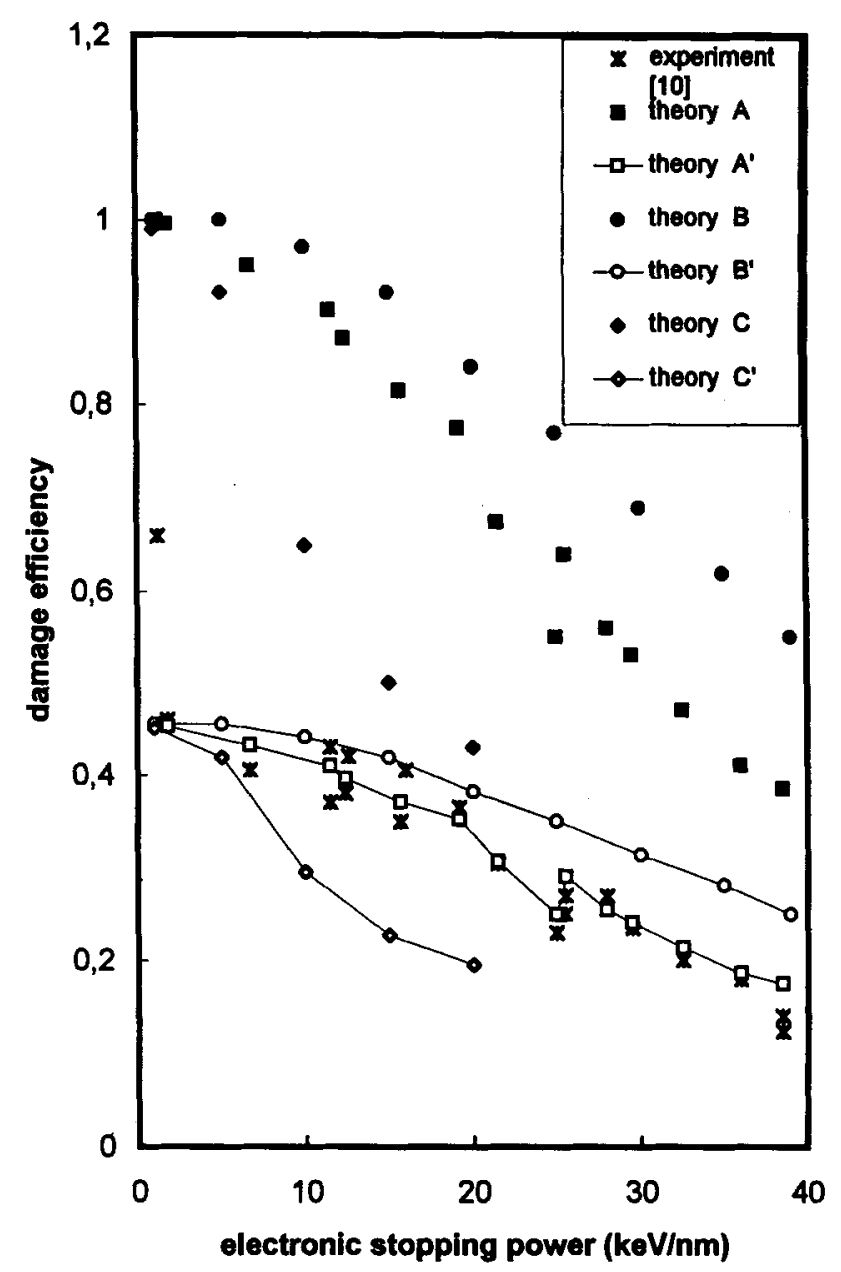

Figure 3. The variation of calculated and experimental damage efficiencies in iron vs $S_{\mathrm{e}}$. Initial conditions of calculation are defined by the experimental conditions (Dunlop et al 1994). Three values of the electron phonon coupling have been tested: (A) $g=14.4 \times 10^{11} \mathrm{~W} \mathrm{~cm}^{-3} \mathrm{~K}^{-1}$, (B) $g=7 \times 10^{11} \mathrm{~W} \mathrm{~cm}^{-3} \mathrm{~K}^{-1}$ and (C) $g=30 \times 10^{11} \mathrm{~W} \mathrm{~cm}^{-3} \mathrm{~K}^{-1}$. A factor of 0.45 (curve $\mathrm{A}^{\prime}$, $B^{\prime}$ and $C^{\prime}$ ) is applied to the curves $A, B$ and $C$ (see the text) to make a comparison with the experimental data. The best agreement is obtained for the curve $\mathrm{A}^{\prime}$.

The damage efficiency evolution has been calculated for two other values of the electron-phonon coupling with a beam energy of $12 \mathrm{MeV} \mathrm{amu}{ }^{-1}: g=7 \times 10^{+11}$ and $30 \times 10^{+11} \mathrm{~W} \mathrm{~cm}^{-3} \mathrm{~K}^{-1}$ for a beam energy of $12 \mathrm{MeV}$ $\mathrm{amu}^{-1}$. The results of the calculation are reported in figure 3. Applying the same factor $F=0.45$ one can better appreciate the sensitivity of our calculation leading to the determination of the electron phonon coupling in iron. Knowing that the electron phonon coupling is proportional to the square of the electronic density (Wang et al 1994, 1995), the density of electrons participating in the energy diffusion is in between $5.5 \times 10^{+22}$ and $1.15 \times 10^{+23}$ electrons $\mathrm{cm}^{-3}$.

\subsection{Defect annealing in nickel}

The studies of defect annealing in nickel under energetic 
particle irradiations have been the first to be reported (Coltman et al 1967; Lampert and Schaefer 1972; Forsch et al 1974; Knöll et al 1974; Vajda 1977; Iwase et al 1987, 1988, 1990, 1992a; Dunlop and Lesueur 1993; Dammak 1994; Iwase and Iwata 1994). According to the analysis of irradiation effects in iron induced by $S_{\mathrm{e}}$, similar calculations have been performed in nickel. Because of the lack of experimental data of activation energies of substages for stage I defect recovery, only the substage $I_{\mathrm{D}+\mathrm{E}}$ is considered here (table 1). Some parameters of nickel used in the calculations are given in tables 1 and 2. All the other thermal parameters used in the calculations are taken from earlier studies (Johnson 1961; Weast 1976-1977; Brandes 1983; Kittel 1983; Lide 1992-1993; Wang et al 1994, 1995).

As the electron-phonon coupling factor $g$ is considered as a free parameter, we used $g(300 \mathrm{~K}, \mathrm{Ni})=1.0 \times 10^{12}$, $2.3 \times 10^{12}$ and $4.1 \times 10^{12} \mathrm{~W} \mathrm{~cm}^{-3} \mathrm{~K}^{-1}$ for $z=1,1.5$ and 2 (Wang et al 1994, 1995), respectively where $z$ is the number of electrons per atom.

In figure 5 , the comparison between $\xi_{\text {cal }}$ and $\xi_{\text {exp }}$ is given for nickel. The $\xi_{\text {exp }}$ values are taken from Iwase et al (1986, 1988) and Iwase and Iwata (1994) and the error bars represent $15 \%$ of the experimental data. The calculations are performed for the three values of $g$ (Wang et al 1994, 1995; Dufour et al 1996). As it is explained in the case of iron, the comparison between

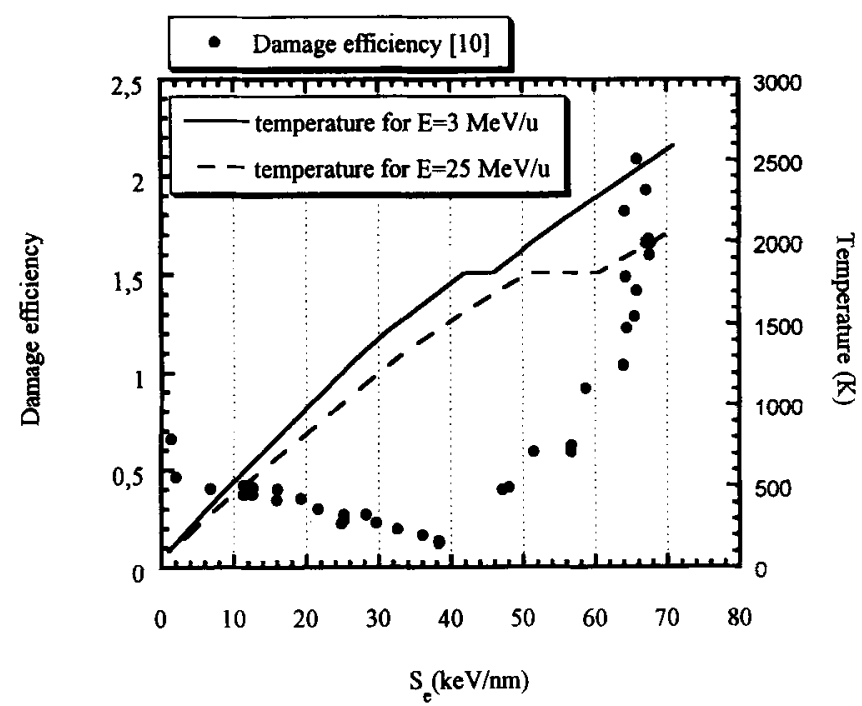

Figure 4. The variation of experimental damage efficiency $\xi_{\exp }$ (Dunlop et al 1994) and calculated maximum lattice temperature $T_{1}$ (in a cylinder radius of $0.3 \mathrm{~nm}$ around the ion path) in iron vs electronic energy loss. In the calculations, substrate temperature is $20 \mathrm{~K}$ and $g(300 \mathrm{~K})=$ $1.44 \times 10^{12} \mathrm{~W} \mathrm{~cm}^{-3} \mathrm{~K}^{-1}$ (Wang et al 1994, 1995). For $T_{1}<T_{\mathrm{m}}$ $\left(T_{\mathrm{m}}=1809 \mathrm{~K}\right), \xi_{\exp }$ decreases with increasing $S_{e}$. For $T_{1}>T_{\mathrm{m}}$, $\xi_{\text {exp }}$ increases with increasing $S_{e}$. The theoretical thresholds for defect creation by $S_{\mathrm{e}}$ in iron are 46 and $60 \mathrm{keV} / \mathrm{nm}$ for $3 \mathrm{MeV}$ $\mathrm{amu}^{-1}$ and $25 \mathrm{MeV} \mathrm{amu}^{-1}$ ion irradiation respectively, showing the velocity effect. experiments is made with a normalized value of $\xi_{\text {cal }}$ : $\xi_{\text {cal }}^{\prime}=0.38 \xi_{\text {cal }}$. Taking into account the uncertainties of the experimental data, figure 5 shows the appearance of defect annealing due to $S_{e}$. We cannot precisely determine the $z$ value for nickel because of the lack of experimental data between 10 and $25 \mathrm{keV} / \mathrm{nm}$. But in a first approach $z=1$ gives the best fit of the experimental data. In the case of $g=10^{12} \mathrm{~W} \mathrm{~cm}^{-3} \mathrm{~K}^{-1}$, from our calculation, damage creation cannot be reached by ion irradiations. The only possibility will be to use cluster beams (fullerenes for example (Dunlop et al 1996)) leading to high values of $S_{\mathrm{e}}$ at very low velocity: in that case damage creation by electronic stopping power should appear for $S_{\mathrm{c}}$ larger than $70 \mathrm{keV} \mathrm{nm}^{-1}$.

\section{Concluding remarks}

A method is proposed to explain the defect annealing and to calculate the thresholds of defect creation in metals induced by electronic energy loss. First, the distribution of defects created in metals by nuclear

\section{Target: Nickel at $20 \mathrm{~K}$}

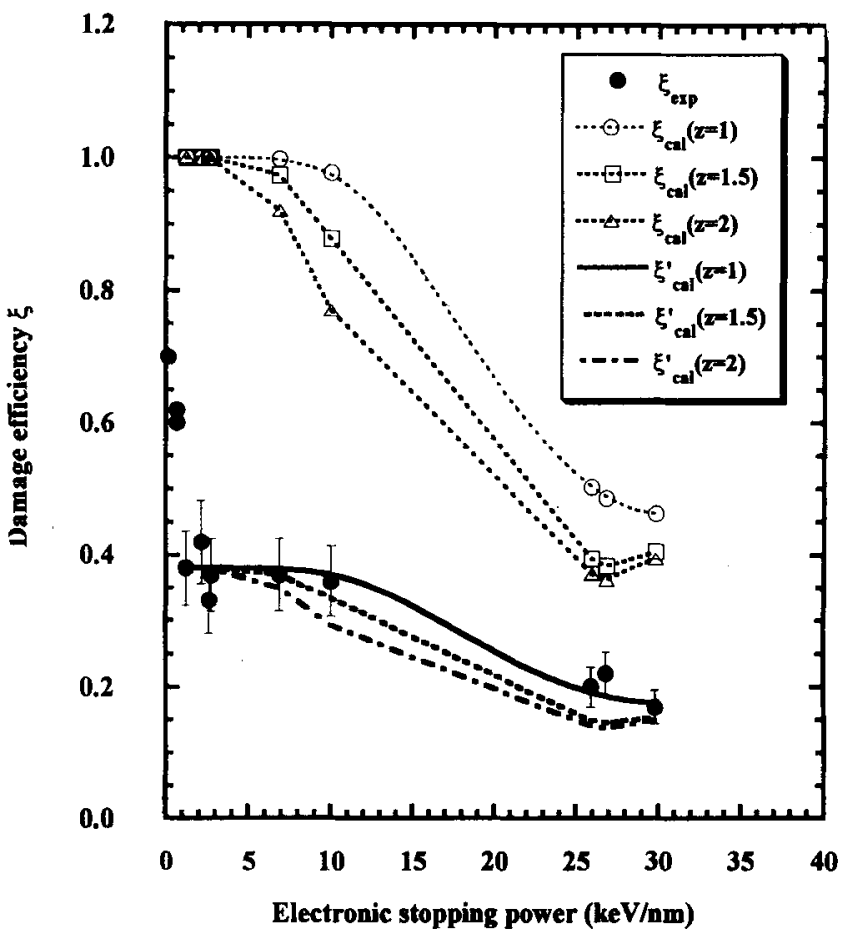

Figure 5. The calculated and experimental damage efficiencies ( $\xi_{\text {cal }}$ and $\xi_{\text {exp }}$ ) in nickel vs electronic stopping power $S_{e}$. The experimental data are taken from Iwase et al $(1986,1988)$ and Iwase and Iwata (1994) and the error bars are taken as $\pm 15 \%$ of the experimental data. $\xi_{\text {cal }}^{\prime}$ is given by $\xi_{\text {cal }}^{\prime}=F \xi_{\text {cal }}$ with $F=0.38$. For the calculations, the substrate temperature is $20 \mathrm{~K}$, the ions are the same as in the experiments of Iwase et al (1986, 1988) and Iwase and Iwata (1994). The values of electron-phonon coupling at $300 \mathrm{~K}$ are $1.0 \times 10^{12}, 2.3 \times 10^{12}$ and $4.1 \times 10^{12} \mathrm{~W} \mathrm{~cm}^{-3} \mathrm{~K}^{-1}$ for $z=1,1.5$ and 2 , respectively. 
collisions was numerically calculated. Second, in the framework of $S_{c}$ induced thermal spike, $S_{e}$ induced defect annealing is simulated without the consideration of athermal recombination. This type of $S_{c}$ induced defect annealing is due to the thermally activated migration of close pair defects. The close agreement between calculation and experiment supports the idea that local temperature can be effective in defect annealing along the ion path. Consequently the threshold of defect creation can be ascribed to the appearance of a melt phase in the material.

For iron, by the use of a unique value of electronphonon coupling $g=1.44 \times 10^{12} \mathrm{~W} \mathrm{~cm}^{-3} \mathrm{~K}^{-1}$, one can calculate in agreement with the experiment: (i) the damage efficiency taking into account a proportionality factor of 0.45 ; (ii) the thresholds for $S_{e}$ induced defect creation at $S_{c}=46$ to $60 \mathrm{keV} / \mathrm{nm}$ for 3 and $25 \mathrm{MeV} / \mathrm{amu}$ ion irradiations, respectively. For nickel more experimental data are needed to test the predictions of the thermal spike model.

\section{References}

Allen P B 1987 Phys. Rev. Lett. 591460

Averback R S and Merkle K L 1977 Phys. Rev. B16 3860

Barbu A, Dunlop A, Henry J, Lesueur D and Lorenzelli N 1992 Mater. Sci. Forum 97-99 577

Bauer W, Herschbach K and Jackson J J 1969 Phys. Rev. 185 924

Biersack J P and Haggmark L G 1980 Nucl. Instr. Meth. 174 257

Birtcher R C, Lwin Y and Koehler J S 1974 Phys. Rev. Lett. 33899

Bitensky I S and Parilis E S 1987 Nucl. Instr. Meth. Phys. Res. B21 26

Bois P and Beuneu F 1989 J. Phys: Condens. Matter 14535 Brandes E A 1983 Metals (London: Butterworths) 6th ed.

Campendium A 1961 Properties of materials at low temperatures (ed.) V J Johnson (Oxford: Pergamon)

Chadderton L T and Montagu-Pollock H 1969 Proc. R. Soc. A274 239

Coltman R R, Klabunde C E and Redman J K 1967 Phys. Rev. 156715

Corbert J W, Smith R B and Walker R M 1959 Phys. Rev. 1141452

Dammak H 1994 Thèse (Ecole Polytechnique) Rapport CEA-R5668

Dammak H, Barbu A, Dunlop A, Lesueur D and Lorenzelli N 1993a Philos. Mag. Lett. 67253

Dammak H, Lesueur D, Dunlop A, Legrand P and Morillo J 1993b Radiat. Eff. \& Def. Sol. 126111

Dammak H, Dunlop A, Lesueur D, Brunelle A, Della-Negra S and Le Beyee Y 1995 Phys. Rev. Lett. 741135

Dausinger F and Schultz H 1975 Phys. Rev. Lett. 351773

Delaplace J, Nicoud J C, Schumacher D and Vogl G 1968 Phys. Status Solidi 29819

Diaz de la Rubia T and Guina M W 1991 Phys. Rev. Lett. 66 2766
Dibbert H J, Sonnenberg K, Schilling W and Dedek U 1972 Radiat. Eff. 15115

Dufour C 1993 Thèse (Universite de Caen) Rapport CEA-R-5638

Dufour C et al 1993 J. Phys.: Condens. Matter 54573

Dufour C, Paumier E and Toulemonde M 1993 Radiat. Eff. \& Def. Sol. 126119

Dufour C, Wang Z G, Levalois M, Marie Ph, Paumier E, Pawlak F and Toulemonde M 1996 Nucl. Instr. Meth. B107 218

Dunlop A and Lesueur D 1989 Radiat. Eff. \& Def. Sol. 108 337

Dunlop A and Lesueur D 1992 Mater. Sci. Forum 97-99 553

Dunlop A and Lesueur D 1993 Radiat. Eff. \& Def. Sol. 126 123

Dunlop A, Pande B M, Böning K, Rosner P and Schaefer H E $1982 \mathrm{~J}$. Nucl. Mater. 108/10983

Dunlop A, Boulanger L, Lesueur D, Lorenzelli N and Toulemonde M 1987 Mater. Sci. Forum 15-18 1117

Dunlop A, Lorenzelli N and Mansel W 1988 Nucl. Instr. Meth. Phys. Res. $\mathrm{B33} 706$

Dunlop A, Lesueur D and Dural J 1989a Nucl. Instr. Meth. Phys. Res. B42 182

Dunlop A, Lesueur D, Jaskierowicz G and Schildknecht J 1989 Nucl. Instr. Meth. Phys. Res. B36 412

Dunlop A, Lesueur D, Morillo J, Dural J, Spohr R and Vetter J 1990 Nucl. Instr. Meth. Phys. Res. B48 419

Dunlop A, Legrand P, Lesueur D, Lorenzelli N, Morillo J, Barbu A and Bouffard S 1991 Europhys. Lett. 15765

Dunlop A, Lesueur D, Legrand P, Dammak $\mathrm{H}$ and Dural J 1994 Nucl. Instr. Meth. Phys. Res. B90 330

Dunlop A, Dammak H and Lesueur D 1996 Nucl. Instr. Meth. B112 23

Dural J, Ardonceau J and Jousset J C 1977 J. Phys. T38 1007

Fleischer R L, Price P B and Walker R M 1975 Nuclear tracks in solids: Principles and applications (Berkeley: University of California Press)

Forsch K, Hemmerich J, Knöll H and Lucki G 1974 Phys. Status Solidi A23 223

Hamada T, Yamakawa K and Fujita F E 1981 J. Phys. F11 657

Henry J, Barbu A, Leridon B, Lesueur D and Dunlop A 1992 Nucl. Instr. Meth. Phys. Res. B67 390

Iwase A and Iwata T 1994 Nucl. Instr. Meth. Phys. Res. B90 322

Iwase A, Sasaki S, Iwata T and Nihira T $1985 \mathrm{~J}$. Nucl. Mater. $133 \& 134365$

Iwase A, Sasaki S, Iwata T and Nihira T $1986 \mathrm{~J}$. Nucl. Mater. 141-143 786

Iwase A, Sasaki S, Iwata T and Nihira T 1987 Phys. Rev. Lett. 582450

Iwase A, Sasaki S, Iwata T and Nihira T $1988 \mathrm{~J}$. Nucl. Mater. 155-157 1188

Iwase A, Iwata T, Sasaki S and Nihira T $1990 \mathrm{~J}$. Phys. Soc. Jap. 591451

Iwase A, Iwata T, Sasaki S, Nihira T and Sasaki S 1992a Mater. Sci. Forum 97-99605

Iwase A, Iwata T and Nihira T 1992b J. Phys. Soc. Jap. 61 3878

Kaganov M I, Lifshitz I M and Tanatarov L V 1957 Sov. Phys. -JETP 4173

Kittel C 1983 Physique de l'etat solide (Paris: Bordas) $5^{\text {ieme }} \mathrm{ed}$ 
Knöll H, Dedek U and Schilling W 1974 J. Phys. F: Metal Phys. 41095

Lampert G and Schaefer H E 1972 Phys. Status Solidi $\mathbf{B 5 2} 475$

Lesueur D and Dunlop A 1993 Radiat. Eff. \& Def. Sol. 126163

Lide D R (ed.) 1992-1993 Handbook of chemistry and physics (Boca Raton, FL: Chemical Rubber Co.) 73rd ed.

Maury F, Vajda P, Lucasson A and Lucasson P 1973 Phys. Rev. B8 5496, 5506

Maury F, Bigot M, Vajda P, Lucasson A and Lucasson P 1976 Phys. Rev. B14 5303

Mcllwain J, Gardiner R, Sosin A and Myhra S 1975 Radiat. Eff. 2419

Meftah A et al 1994 Phys. Rev. B49 12457

Myhra S and Gardiner R B 1975 Radiat. Eff. 2735

Nakagawa M, Böning K, Rosner P and Vogl G 1977 Phys. Rev. B16 5285

Paumier E, Bogdanski P, Dural J, Girard J P and Toulemonde M 1989a Radiat. Eff. \& Def. Sol. 110117

Paumier E, Toulemonde M, Dural J, Rullier-Albenque F, Girard J P and Bogdanski P 1989b Europhys. Lett. 10555

Paumier E et al 1992 Mater. Sci. Forum 97-99 599 Paumier E et al 1993 Radiat. Eff. \& Def. Sol. 126181

Schaefer H E and Lampert G 1972 Phys. Status Solidi B53 113
Seitz F and Kochler J S 1956 Solid State Phys. 2305

Simpson H M and Chaplin R L 1969 Phys. Rev. 1781166

Toulemonde M, Dufour C and Paumier E 1992 Phys. Rev. B46 14362

Toulemonde M, Paumier E and Dufour C 1993 Radiat. Eff. \& Def. Sol. 126201

Toulemonde M, Dufour C, Wang Z G and Paumier E 1996 Nucl. Instr. Meth. B112 1996

Vajda P 1977 Rev. Mod. Phys. 49481

Vineyard G H 1976 Radiat. Eff. 29245

Wang Z G, Dufour C, Paumier E and Toulemonde M 1994 J. Phys.: Condens. Matter 66733

Wang Z G, Dufour C, Paumier E and Toulemonde M $1995 \mathrm{~J}$. Phys.: Condens. Matter 72525

Wang Z G, Dufour C, Cabeau B, Dural J, Fuchs G, Paumier E, Pawlak F and Toulemonde M 1996a Nucl. Instr. Meth. B107 175

Wang Z G, Dufour C, Paumier E and Toulemonde M 1996b Nucl. Instr. Meth. B115 577

Weast R C (ed.) 1976-1977 Handbook of chemistry and physics (Boca Raton, FL: Chemical Rubber Co.) 57th ed.

Wells J and Russell K C 1976 Radiat. Eff. 28157

Young F W Jr 1978 J. Nucl. Mater. 69-70 310 